\title{
Enhanced Bactericidal Activity of Rifampin and/or Pyrazinamide When Combined with PA-824 in a Murine Model of Tuberculosis ${ }^{\nabla}$
}

\author{
Rokeya Tasneen, Sandeep Tyagi, Kathy Williams, Jacques Grosset, and Eric Nuermberger* \\ Center for Tuberculosis Research, Johns Hopkins University, Baltimore, Maryland
}

Received 25 May 2008/Returned for modification 28 July 2008/Accepted 4 August 2008

\begin{abstract}
PA-824 is in phase II clinical testing to treat tuberculosis. At a dose of $100 \mathrm{mg} / \mathrm{kg}$ of body weight, it has demonstrated bactericidal activity during the initial and continuation phases of treatment in a murine model of tuberculosis. In a prior study, substitution of PA-824 for isoniazid in the first-line regimen of rifampin, isoniazid, and pyrazinamide resulted in significantly lower CFU counts at 2 months and shorter time to culture-negative conversion. However, the study design prevented a rigorous assessment of the relapse rate after completion of therapy. The current experiment was designed to assess (i) the extent of the beneficial effect of substituting PA-824 for isoniazid in the first-line regimen, (ii) the influence of the PA-824 dose on the same effect, and (iii) the activity of each one-, two-, and three-drug combination of rifampin, PA-824, and pyrazinamide. Mice were infected by the aerosol route and initiated on treatment 14 days later with more than $7 \log _{10}$ CFU per lung. Treatment with rifampin and pyrazinamide was more effective than treatment with rifampin, isoniazid, and pyrazinamide at reducing the lung CFU count, consistent with past evidence of isoniazid's antagonism in this model. The addition of PA-824 at 12.5 and $25 \mathrm{mg} / \mathrm{kg} / \mathrm{day}$ did not increase the activity of rifampin plus pyrazinamide, but the addition of $P A-824$ at 50 and $100 \mathrm{mg} / \mathrm{kg} / \mathrm{day}$ did increase the activity in a dose-dependent manner. The combination of rifampin, PA-824 (100 mg/kg), and pyrazinamide rendered all mice culture negative after 2 months of treatment and free of relapse after $\mathbf{4}$ months of treatment, while some mice receiving rifampin, isoniazid, and pyrazinamide remained culture positive and $15 \%$ relapsed after completing 4 months of treatment. The two-drug combination of PA-824 and pyrazinamide displayed synergistic activity that was equivalent to that of the standard first-line regimen. Together, these results support the evaluation of regimens based on the combination of rifampin, PA-824, and pyrazinamide in phase II clinical trials while demonstrating several potential pitfalls in the evaluation of new drug combinations in a murine model of tuberculosis.
\end{abstract}

PA-824 $(\mathrm{Pa})$ is a novel nitroimidazo-oxazine in phase II clinical testing to treat tuberculosis (TB). It has an MIC of $0.125 \mu \mathrm{g} / \mathrm{ml}(13)$, a unique mechanism of action against $\mathrm{Myco}$ bacterium tuberculosis, and no known cross-resistance with existing TB drugs (15). At a dose of $100 \mathrm{mg} / \mathrm{kg}$ of body weight, it has demonstrated bactericidal activity during the initial and continuation phases of treatment in a murine model of TB $(8$, 16). Together, these properties have engendered optimism that $\mathrm{Pa}$ may have the potential to shorten the duration of treatment for drug-susceptible and/or multidrug-resistant TB (MDR-TB). In a recent long-term study of a mouse model, we found that the addition of $\mathrm{Pa}$ to the rifampin, isoniazid, and pyrazimamide (RIF-INH-PZA) combination had no effect on lung CFU counts (10). While the substitution of $\mathrm{Pa}$ for RIF or PZA was detrimental, its substitution for INH resulted in significantly lower CFU counts at 2 months and shorter time to culture-negative conversion in the lungs. However, the study design prevented a rigorous assessment of the relapse rate after completion of therapy $(2,10)$. The potential benefit of substituting $\mathrm{Pa}$ for INH is important to characterize because INH is known to have antagonistic activity on the activity of RIF-PZA in a murine model such that simply removing INH

\footnotetext{
* Corresponding author. Mailing address: Center for Tuberculosis Research, Johns Hopkins University, 1550 Orleans Street, Baltimore, MD 21231-1002. Phone: (410) 502-0580. Fax: (410) 614-8173. E-mail: enuermb@jhmi.edu.

${ }^{\nabla}$ Published ahead of print on 11 August 2008.
}

from a regimen containing RIF-PZA is beneficial $(6,7,12)$. Furthermore, because $\mathrm{Pa}$ has dose-dependent bactericidal activity when administered alone, it may be important to define the exposure threshold necessary for effect when $\mathrm{Pa}$ is added to RIF-PZA, as this threshold may then become a target for early clinical investigations of the pharmacokinetics and pharmacodynamics of $\mathrm{Pa}$ as well as for the future development of related compounds.

The current experiment was designed to assess (i) the extent of the beneficial effect of substituting Pa for INH in the RIFINH-PZA regimen, (ii) the influence of the $\mathrm{Pa}$ dose on the activity of RIF-Pa-PZA, and (iii) the activity of each one-, two-, and three-drug component of RIF-Pa-PZA.

\section{MATERIALS AND METHODS}

Bacterial strain. Mycobacterium tuberculosis $\mathrm{H} 37 \mathrm{Rv}$ was passaged in mice and frozen in aliquots at $-80^{\circ} \mathrm{C}$. After thawing, an aliquot was subcultured in Middlebrook 7 H9 broth (Fisher, Pittsburgh, PA) with $10 \%$ oleic acid-albumin-dextrose-catalase (OADC) (Difco, Detroit, MI) and $0.1 \%$ Tween 80 (Sigma, St. Louis, MO).

The MICs for M. tuberculosis H37Rv strain are as follows: RIF, $0.25 \mu \mathrm{g} / \mathrm{ml}$; INH, $0.05 \mu \mathrm{g} / \mathrm{ml}$; and $\mathrm{Pa}, 0.125 \mu \mathrm{g} / \mathrm{ml}$ on $7 \mathrm{H} 10$ medium; and PZA, $10 \mu \mathrm{g} / \mathrm{ml}$ on Löwenstein-Jensen medium ( $\mathrm{pH} 5.5$ ).

Antimicrobials. Pa was provided by the Global Alliance for TB Drug Development (New York, NY). For susceptibility testing and administration to mice, $\mathrm{Pa}$ was suspended in a cyclodextrin micelle formulation (CM-2) as previously described (16). A 50-mg/ml suspension was prepared monthly, and dilutions in distilled water were made weekly to give the desired concentrations. Suspensions used for oral administration were shaken between doses to ensure uniform 
TABLE 1. Experimental scheme to evaluate the additive effect of PA-824 combined with rifampin and/or pyrazinamide

\begin{tabular}{|c|c|c|c|c|c|c|c|c|c|c|}
\hline \multirow{3}{*}{ Regimen $^{a}$} & \multicolumn{9}{|c|}{ No. of mice sacrificed at the following time point ${ }^{b}$ : } & \multirow{3}{*}{$\begin{array}{l}\text { Total no. } \\
\text { of mice }\end{array}$} \\
\hline & \multicolumn{2}{|c|}{$\begin{array}{l}\text { Before } \\
\text { treatment }\end{array}$} & \multicolumn{4}{|c|}{ On treatment } & \multicolumn{3}{|c|}{ After treatment } & \\
\hline & $\mathrm{D}-13$ & D0 & M2 & M4 & M5 & M6 & $\mathrm{M} 4(+3)$ & M5(+3) & $\mathrm{M} 6(+3)$ & \\
\hline \multicolumn{11}{|l|}{ Control groups } \\
\hline Group 1 (untreated) & 5 & 5 & & & & & & & & 10 \\
\hline Group 2 (2RHZ/4RH) & & & 5 & 5 & 5 & 5 & 20 & 20 & 20 & 80 \\
\hline Group 3 (2RZ/3R) & & & 5 & 5 & 5 & & 20 & 20 & & 55 \\
\hline Group 4 (5RZ) & & & & 5 & 5 & & 20 & 20 & & 50 \\
\hline Group $5(2 \mathrm{R})$ & & & 5 & & & & & & & 5 \\
\hline Group $6\left(2 \mathrm{~Pa}_{100}\right)$ & & & 5 & & & & & & & 5 \\
\hline \multicolumn{11}{|l|}{ Test groups } \\
\hline Group $7\left(5 \mathrm{RPa}_{100}\right)$ & & & 5 & 5 & 5 & & & & & 15 \\
\hline Group $8\left(2 \mathrm{~Pa}_{100} \mathrm{Z} / 3 \mathrm{~Pa}\right)$ & & & 5 & 5 & 5 & & & & & 15 \\
\hline Group $9\left(5 \mathrm{~Pa}_{100} \mathrm{Z}\right)$ & & & & 5 & 5 & & & & & 10 \\
\hline Group $10\left(2 \mathrm{RPa}_{12.5} \mathrm{Z} / 3 \mathrm{RPa}\right)$ & & & 5 & 5 & 5 & & 20 & & & 35 \\
\hline Group $11\left(2 \mathrm{RPa}_{25} \mathrm{Z} / 3 \mathrm{RPa}\right)$ & & & 5 & 5 & 5 & & & & & 15 \\
\hline Group $12\left(2 \mathrm{RPa}_{50} \mathrm{Z} / 3 \mathrm{RPa}\right)$ & & & 5 & 5 & 5 & & & & & 15 \\
\hline Group $13\left(2 \mathrm{RPa}_{100} \mathrm{Z} / 3 \mathrm{RPa}\right)$ & & & 5 & 5 & 5 & & 20 & 20 & & 55 \\
\hline Total & & & & & & & & & & 365 \\
\hline
\end{tabular}

dosing. Other drugs were purchased from Sigma or Fisher (PZA), and solutions were prepared weekly in distilled water and stored at $4^{\circ} \mathrm{C}$.

Aerosol infection. Six-week-old female BALB/c mice (Charles River, Wilmington, MA) were infected with approximately $3.5 \log _{10}$ CFU of M. tuberculosis H37Rv from a late-log-phase broth culture (optical density at $600 \mathrm{~nm}$ of approximately 0.8 ) using the inhalation exposure system (Glas-Col Inc., Terre Haute, IN). Five mice were sacrificed the following day (day -13 [D-13]) to determine the number of CFU implanted in the lungs. All procedures involving animals were approved by the Institutional Animal Care and Use Committee.

Drug treatment. After infection, mice were randomized into one of the 13 treatment groups depicted in Table 1. Groups 1 through 6 were control groups that included untreated mice as a negative control and mice treated with 2 months of the combination RIF, INH, and PZA followed with 4 months of RIF and INH as the standard positive control. In addition, groups 3 and 4 were treated with the combination of RIF and PZA as controls for the potential benefit of adding Pa. Groups 5 and 6 were treated with RIF and Pa alone, respectively, to determine the individual contribution of each drug. Group 7 and groups 8 and 9 were test groups to evaluate the benefit of adding RIF to Pa and PZA to Pa, respectively. Finally, groups 10 through 13 were used to determine the effect of increasing the daily dose of Pa from $12.5 \mathrm{mg} / \mathrm{kg}$ (the minimum effective dose in monotherapy) to $100 \mathrm{mg} / \mathrm{kg}$ (the minimum bactericidal dose in monotherapy) in combination with RIF-PZA (16).

Treatment began 14 days after infection on day 0 (D0). Five untreated mice were sacrificed on D0 to determine the baseline lung CFU count. All drugs were administered in $0.2 \mathrm{ml}$ by gavage 5 days per week. The drugs and dosages were INH $(25 \mathrm{mg} / \mathrm{kg})$, RIF $(10 \mathrm{mg} / \mathrm{kg})$, and PZA $(150 \mathrm{mg} / \mathrm{kg})$ as previously described (5). Pa was administered at $100 \mathrm{mg} / \mathrm{kg}$ unless described otherwise (16). RIF was administered at least $1 \mathrm{~h}$ before other drugs to avoid an adverse pharmacokinetic interaction (3-5).

Monotherapy regimens with RIF and Pa were given for only the first 2 months, while combination regimens were given for 5 months, with the exception of regimen 2, the standard regimen, which was given for 6 months. Five mice per group were sacrificed monthly, beginning after 2 months of treatment, to determine lung CFU counts. In groups treated with RIF-INH-PZA, RIF-PZA, RIF$\mathrm{Pa}_{12.5}$-PZA (RIF-Pa-PZA regimen with $12.5 \mathrm{mg}$ of $\mathrm{Pa} / \mathrm{kg}$ ), and RIF-Pa ${ }_{100}-\mathrm{PZA}$ regimens, 20 additional mice were held for 3 months after the completion of treatment for selected durations to determine the proportion with culture-positive relapse. The number of mice held for relapse was based on calculations showing that statistical power of $>80 \%$ is maintained for detecting $\geq 45$ percentage point differences in the proportion of mice relapsing after treatment with the two RIF-Pa-PZA test regimens compared to the RIF-INH-PZA or RIF-PZA control regimen.

Assessment of treatment efficacy. Whole lungs were homogenized in $2.5 \mathrm{ml}$ of phosphate-buffered saline, and quantitative cultures of the homogenate were performed by plating serial dilutions on selective oleic acid-albumin-dextrosecatalase-enriched 7H11 agar medium (Becton-Dickinson, Sparks, MD). When counts below $300 \mathrm{CFU}$ were anticipated or whenever relapse was assessed, the entire lung homogenate was plated on five plates. Relapse was defined by $\geq 1$ detectable CFU.

Susceptibility testing to Pa and RIF. To test isolates for susceptibility to $\mathrm{Pa}$ and RIF, colonies were scraped together, suspended in phosphate-buffered saline, homogenized with glass beads, and plated in serial dilutions on $7 \mathrm{H} 11$ agar with or without $2 \mu \mathrm{g} / \mathrm{ml}$ of Pa or RIF. Resistance was defined as growth on drug-containing plates of $>1 \%$ of the number of colonies isolated on plain plates.

Statistical analysis. Lung CFU counts were log transformed before analysis as $\log _{10}(x+1)$, where $x$ is the absolute CFU count. Differences in group mean CFU counts were compared by one-way analysis of variance with Bonferroni's posttest, using GraphPad Prism v.4.01 (GraphPad, San Diego, CA). Differences in proportions were compared by Fisher's exact test, using STATA 8.2 (STATA Corp., College Station, TX). Adjustments were made for multiple comparisons when necessary.

\section{RESULTS}

Change in CFU counts during the initial 2-month phase of treatment. One day after aerosol infection, the mean lung CFU count was $\log _{10} 3.49 \pm 0.33$. Treatment began 13 days later, on D0, when the mean lung CFU count was $\log _{10} 7.11 \pm$ 0.25 . Among the positive controls, groups 2 to 6 , the most powerful activity was observed in groups 3 and 4 treated with RIF-PZA ( $P<0.01$ versus RIF-INH-PZA). In these mice, the mean lung CFU count was reduced to $\log _{10} 0.77 \pm 0.38$ (Table 2 ). The next most active regimen was the standard combination RIF-INH-PZA, which reduced the mean CFU count to $\log _{10}$ $1.95 \pm 0.28$. Treatment with $\mathrm{RIF}$ alone and $\mathrm{Pa}$ alone reduced the mean CFU counts to $\log _{10} 3.94 \pm 0.43$ and $\log _{10} 4.38 \pm$ 
TABLE 2. Results of lung CFU counts assessed during treatment

\begin{tabular}{|c|c|c|c|c|c|}
\hline \multirow{2}{*}{ Regimen $^{a}$} & \multicolumn{5}{|c|}{ Mean lung $\log _{10}$ CFU count \pm SD at the indicated time point ${ }^{b}$ : } \\
\hline & D0 & M2 & M4 & M5 & M6 \\
\hline \multicolumn{6}{|l|}{ Control groups } \\
\hline Group 1 (untreated) & $7.11 \pm 0.25$ & & & & \\
\hline Group 2 (2RHZ/4RH) & & $1.95 \pm 0.28$ & $0.70 \pm 0.70$ & 0 & 0 \\
\hline Group $3(2 R Z / 3 R)$ & & $0.77 \pm 0.38$ & $0.48 \pm 1.07$ & 0 & ND \\
\hline Group 4 (5RZ) & & & 0 & 0 & ND \\
\hline Group $5(2 \mathrm{R})$ & & $3.94 \pm 0.43$ & ND & ND & ND \\
\hline Group $6\left(2 \mathrm{~Pa}_{100}\right)$ & & $4.38 \pm 0.45$ & ND & ND & ND \\
\hline \multicolumn{6}{|l|}{ Test groups } \\
\hline Group $7\left(5 \mathrm{RPa}_{100}\right)$ & & $3.29 \pm 0.18$ & $0.79 \pm 0.60$ & 0 & ND \\
\hline Group $8\left(2 \mathrm{~Pa}_{100} \mathrm{Z} / 3 \mathrm{RPa}\right)$ & & $1.87 \pm 0.26$ & $1.06 \pm 1.29^{c}$ & $1.32 \pm 1.56^{c}$ & ND \\
\hline Group $9\left(5 \mathrm{~Pa}_{100} \mathrm{Z}\right)$ & & & $0.38 \pm 0.53^{c}$ & $0.31 \pm 0.70^{c}$ & ND \\
\hline Group $10\left(2 \mathrm{RPa}_{12.5} \mathrm{Z} / 3 \mathrm{RPa}\right)$ & & $0.76 \pm 0.53$ & $0.06 \pm 0.13$ & 0 & ND \\
\hline Group $11\left(2 \mathrm{RPa}_{25} \mathrm{Z} / 3 \mathrm{RPa}\right)$ & & $0.84 \pm 0.19$ & 0 & 0 & ND \\
\hline Group $12\left(2 \mathrm{RPa}_{50} \mathrm{Z} / 3 \mathrm{RPa}\right)$ & & $0.31 \pm 0.43$ & 0 & 0 & ND \\
\hline Group $13\left(2 \mathrm{RPa}_{100} \mathrm{Z} / 3 \mathrm{RPa}\right)$ & & 0 & 0 & 0 & ND \\
\hline
\end{tabular}

${ }^{a}$ Regimens are shown as explained in Table 1 , footnote $a$.

${ }^{b}$ Mean lung $\log _{10}$ CFU counts at day 0 (D0) or month 2 (M2), 4, 5, and 6 of treatment. ND, not determined.

${ }^{c}$ Isolates resistant to PA-824.

0.45 , respectively. Although much less active than the previous combinations, each drug had significant bactericidal activity, resulting in CFU reductions of $\log _{10} 3.17$ and $\log _{10} 2.73$, respectively, during the first 2 months of treatment.

Among mice treated with the test regimens, groups 7 to 13, the most powerful activity was observed in groups 10 through 13 treated with the three-drug combination of RIF-Pa-PZA. However, the mean CFU counts in mice in groups 10 and 11 that received $\mathrm{Pa}$ at doses of 12.5 and $25 \mathrm{mg} / \mathrm{kg}$, respectively, were no different from those in mice treated with the RIF-PZA regimen, suggesting that there was no contribution of $\mathrm{Pa}$ to the activity of the three-drug regimen. For group 12, in which mice received $\mathrm{Pa}$ at $50 \mathrm{mg} / \mathrm{kg}$ in combination with RIF-PZA, the mean CFU count was lower than that in mice receiving only RIF-PZA. Although this difference was not statistically significant, the fact that three out of five mice receiving $\mathrm{RIF}-\mathrm{Pa}_{50^{-}}$ PZA were culture negative compared to none of the five mice receiving RIF-PZA further suggests that $\mathrm{Pa}$ at $50 \mathrm{mg} / \mathrm{kg}$ contributed some activity when added to RIF-PZA. Group 13 received $\mathrm{Pa}$ at $100 \mathrm{mg} / \mathrm{kg}$ in combination with RIF-PZA and yielded negative cultures in all five mice, resulting in a mean CFU count significantly lower $(P<0.01)$ than that observed with RIF-PZA and clearly indicating that the addition of $\mathrm{Pa}$ at this dose enhanced the activity of the RIF-PZA combination.

Among mice treated with the two-drug combinations containing $\mathrm{Pa}$, Pa-PZA was more active than RIF-Pa, with the former regimen producing a mean CFU count of $\log _{10} 1.87 \pm$ 0.26 compared to $\log _{10} 3.29 \pm 0.18$ in mice treated with the latter regimen. However, the latter regimen was significantly more active than RIF alone, indicating that $\mathrm{Pa}$ does have additive activity when combined with RIF.

Change in CFU counts during the 4-month continuation phase of treatment. Among positive-control mice, only those treated during the 2-month initial phase with RIF-INH-PZA or RIF-PZA (i.e., groups 2 through 4) were kept on treatment during the continuation phase. Group 2 received RIF-INHPZA during the initial phase and RIF-INH for the next 4 months. After 4 months of treatment, the CFU count had fallen to $\log _{10} 0.70 \pm 0.70$, with one of five mice being culture negative and the others yielding from 1 to 36 colonies. After 5 and 6 months of treatment, all mice were culture negative. Mice receiving RIF-PZA during the initial phase received either RIF alone (group 3) or RIF-PZA (group 4) for the next 3 months. Mice in groups 3 and 4 were culture negative at months 4 and 5 with the exception of a single mouse in group 3 that yielded $251 \mathrm{CFU}$ after 4 months. The isolates were fully susceptible to RIF.

Among mice treated with the test regimens, the best results were again obtained in groups 10 to 13 treated during the continuation phase with RIF-Pa. Whatever the dose of $\mathrm{Pa}$, all mice were culture negative at months 4 and 5, with the exception of a single mouse receiving the $12.5-\mathrm{mg} / \mathrm{kg}$ dose of $\mathrm{Pa}$ that yielded a single colony at month 4 .

The two-drug combinations, RIF-Pa (group 7) and Pa-PZA (groups 8 and 9), were not quite as active as RIF-PZA was, but they compared rather favorably with RIF-INH-PZA. For example, among mice receiving RIF-Pa, one of five mice was culture negative at month 4 and the others had between 2 and $36 \mathrm{CFU}$ contributing to a mean CFU count of $\log _{10} 0.79 \pm$ 0.60 . All five mice were culture negative at month 5 . Therefore, although RIF-Pa was not as active as RIF-INH-PZA over the first 2 months of treatment, the activity was similar if the first 4 months of treatment are considered.

Mice receiving $\mathrm{Pa}-\mathrm{PZA}$ during the 2-month initial phase were treated with either Pa alone (group 8) or Pa-PZA (group 9) for the next 3 months. After 4 months of treatment, three of the five mice treated with $\mathrm{Pa}$ alone during the continuation phase remained culture positive with 3, 45, and 947 colonies, respectively. Isolates from the two mice with the highest CFU counts were resistant to $\mathrm{Pa}$. Similarly, three out of five mice treated with $\mathrm{Pa}-\mathrm{PZA}$ during the continuation phase were culture positive with 1,1 , and 18 colonies, respectively. Again, the mouse with the highest CFU count harbored a Pa-resistant isolate. At month 5, three of the five mice treated with $\mathrm{Pa}$ alone during the continuation phase remained culture positive with 3,800 , and 1,200 colonies, respectively. As seen at month 4, the 
TABLE 3. Results of relapse assessments

\begin{tabular}{llll}
\hline \multicolumn{1}{c}{ Regimen $^{a}$} & \multicolumn{3}{c}{$\begin{array}{c}\text { Proportion of mice (no. of } \\
\text { mice/total no. of mice) } \\
\text { relapsing } 3 \text { mo after treatment } \\
\text { for the following time: }\end{array}$} \\
\cline { 2 - 4 } & 4 mo & 5 mo & 6 mo \\
\hline Control groups & $3 / 20$ & $0 / 20$ & $0 / 19$ \\
Group 2 (2RHZ/4RH) & $3 / 20$ & $2 / 19^{b}$ & $\mathrm{ND}^{c}$ \\
Group 3 (2RZ/3R) & $0 / 20$ & $0 / 20$ & $\mathrm{ND}$ \\
Group 4 (5RZ) & & & \\
& & & $\mathrm{ND}$ \\
Test groups & $4 / 20$ & $\mathrm{ND}$ & $\mathrm{ND}$ \\
Group 10 (2RPa & & & \\
Group 13 $\left(2 \mathrm{RPa}_{100} \mathrm{Z}^{\mathrm{Z}} \mathrm{Z} / 3 \mathrm{RPa}_{12.5}\right)$ & $0 / 20$ & $0 / 18$ & $\mathrm{ND}$ \\
\hline
\end{tabular}

${ }^{a}$ Regimens are shown as explained in Table 1, footnote $a$.

${ }^{b}$ RIF-susceptible isolates.

${ }^{c} \mathrm{ND}$, not determined.

isolates from the two mice with the highest CFU counts were $\mathrm{Pa}$ resistant. Only one of the five mice receiving Pa-PZA during the continuation phase was culture positive, with 36 colonies that were $\mathrm{Pa}$ resistant.

Relapse after completion of treatment. Mice in group 2 treated with the standard short-course regimen were held for relapse after 4, 5, or 6 months of treatment. As shown in Table 3 , the relapse rate was $15 \%$ (3 of 20) after 4 months of treatment and $0 \%$ thereafter. Mice in group 3 received RIF-PZA for 2 months followed by RIF alone. After 4 and 5 months of treatment, the relapse rates were $15 \%$ and $11 \%$, respectively. All isolates were RIF susceptible. Mice in group 4 received RIF-PZA for the entire 4 or 5 months of treatment. There were no relapses after such treatment, indicating that PZA continues to contribute sterilizing activity during the continuation phase when administered with RIF.

Among the test groups, relapse was assessed only in groups 10 and 13. For group 10, the relapse rate after 4 months of treatment was similar to that observed in group 3, indicating that $\mathrm{Pa}$ had no additive effect at $12.5 \mathrm{mg} / \mathrm{kg}$ when added to RIF-PZA. On the other hand, there were no relapses in mice receiving the $100-\mathrm{mg} / \mathrm{kg}$ dose of $\mathrm{Pa}$ in combination with RIFPZA, indicating a sterilizing effect of $\mathrm{Pa}$ at $100 \mathrm{mg} / \mathrm{kg}$ when added to RIF-PZA. The differences in the proportion of mice relapsing in group 13 treated with 2 months of RIF-Pa ${ }_{100}-\mathrm{PZA}$ and then 2 months of RIF-Pa $\mathrm{a}_{100}$ and control mice treated with either 2 months of RIF-PZA and then 2 months of RIF or with 2 months of RIF-INH-PZA and then 2 months of RIF-INH were statistically significant before $(P=0.0359)$ but not after adjustment for multiple comparisons.

\section{DISCUSSION}

Together with previous studies $(8,16)$, the results of the current study provide further evidence that, at $100 \mathrm{mg} / \mathrm{kg}, \mathrm{Pa}$ is a powerful drug during both the initial and continuation phases of experimental chemotherapy for TB in a murine model. Such evidence includes the finding that the combination RIF- $\mathrm{Pa}_{100^{-}}$ PZA was more active than the standard regimen RIF-INHPZA during the 2-month initial phase of treatment and also during the continuation phase when PZA has been removed. The better activity of the Pa-containing regimen was due not only to the removal of INH, a drug for which the antagonistic effect on RIF-PZA is well established $(5,6,10)$, because the RIF-Pa ${ }_{100}-P Z A$ combination was more bactericidal than the RIF-PZA combination during the initial phase of treatment and prevented relapse more effectively when the continuation phase did not include PZA. These data support the evaluation of regimens based on the RIF-Pa-PZA combination in phase II clinical trials, especially if promising results are observed in the ongoing phase I study of the early bactericidal activity of Pa.

A very interesting finding is the remarkable increase in bactericidal activity observed when PZA is added to Pa. Although PZA has very limited activity in this model when used alone (data not shown), the mean lung $\log _{10}$ CFU counts after 2 months of treatment were $4.38 \pm 0.45$ and $1.87 \pm 0.26$ in mice receiving $\mathrm{Pa}$ and $\mathrm{Pa}-\mathrm{PZA}$, respectively, indicating the synergistic activity of the Pa-PZA combination. As recently described (11) and confirmed here, this combination is as active as the standard regimen of RIF-INH-PZA. However, the remarkable bactericidal effect of Pa-PZA was accompanied by the selection of Pa-resistant mutants in the majority of mice after 4 and 5 months of treatment. This indicates that $\mathrm{Pa}$ is a potent bactericidal drug because it rapidly kills susceptible organisms but also suggests that the synergistic effect of PZA does not result from an independent bactericidal action of PZA because if PZA had direct antimicrobial activity, it would have prevented the selection of Pa-resistant mutants. One may speculate that PZA, a drug for which no specific target of action has been identified, modifies the physiology of $M$. tuberculosis in a way that renders it much more susceptible to $\mathrm{Pa}$. A similar enhancement of RIF activity may be responsible for the synergistic activity of RIF-PZA. The fact that RIF-PZA did not select RIF-resistant mutants in this experiment may be explained by the lower frequency of spontaneous mutants resistant to RIF compared to $\mathrm{Pa}(15,16)$. What is certain is that the antituberculosis activity of PZA and its precise contribution to TB treatment remain enigmatic (17).

It is important to raise a caveat related to the crucial role of the positive controls in the assessment of the test regimens. The activities of the test regimens should be appreciated by comparison with that of the positive controls and not in absolute value. For example, in the current study, the mean lung CFU count at baseline was relatively low at $\log _{10} 7.11 \pm 0.25$, and the response to the standard regimen was somewhat more rapid than usual, with a mean lung CFU count of $\log _{10} 1.95 \pm$ 0.28 after 2 months of treatment and a relapse rate of $15 \%$ after only 4 months of treatment. In other recent studies in which treatment began at similar mean CFU counts, the response to the same positive control was more limited, with a typical CFU count reduction of approximately $\log _{10} 4.5$ after 2 months of treatment and relapse rates of 50 to $90 \%$ after 4 months of treatment $(11,13,14)$. If these data are not taken into consideration, there is a risk of overestimating the activity of the test regimens in the current study. This illustrates the classical danger of making comparisons based on historical controls, even within the same model.

We would also like to address the issue of choosing the proper controls. In the present study, the substitution of $\mathrm{Pa}$ at any dose (i.e., from $12.5 \mathrm{mg} / \mathrm{kg}$ to $100 \mathrm{mg} / \mathrm{kg}$ ) for INH improved the activity of the RIF-INH-PZA regimen. A tempting conclusion is that $\mathrm{Pa}$ at any dose is more active than INH. 
However, because past experience has demonstrated antagonism of INH on the activity of RIF-PZA in our mouse model $(6,7,12)$, we included the RIF-PZA regimen without INH as another control. As expected, RIF-PZA was more effective at reducing lung CFU counts than RIF-INH-PZA, confirming this antagonism. If one then looks at the effect of adding increasing doses of $\mathrm{Pa}$ to the combination RIF-PZA, it is readily apparent that $\mathrm{Pa}$ did not add activity when used at doses of 12.5 and $25 \mathrm{mg} / \mathrm{kg}$, which is consistent with the largely bacteriostatic effect of these doses in monotherapy (16). Only $\mathrm{Pa}$ doses between 50 and $100 \mathrm{mg} / \mathrm{kg}$ improved upon the activity of RIF-PZA. Hence, without the proper RIF-PZA control, we could not have determined that the additive effect of $\mathrm{Pa}$ to RIF-PZA is dose dependent and defined the exposure obtained with the $50-\mathrm{mg} / \mathrm{kg}$ dose as the threshold exposure necessary for additive activity. We have found that a single dose of $54 \mathrm{mg} / \mathrm{kg}$ in the mouse produces a maximum concentration of drug in serum of $15.1 \pm 1.1 \mu \mathrm{g} / \mathrm{ml}$ and an area under the concentration-time curve from $0 \mathrm{~h}$ to infinity of $127.5 \pm 17.8$ $\mu \mathrm{g} \cdot \mathrm{h} / \mathrm{ml}$ (data not shown). It remains to be seen whether a similar exposure will be obtained in humans.

These results have broader implications for the evaluation of new drugs in combination with first-line drugs in a murine model of TB by illustrating the significance of the antagonism of INH on the activity of RIF-PZA. This reproducible antagonism is largely responsible for the beneficial effect observed with substituting fluoroquinolones for INH in the standard RIF-INH-PZA regimen $(6,12)$. Whether such antagonism occurs in humans remains an open question. However, as substitution experiments have become a common method for evaluating whether a new drug may contribute additive activity to the existing first-line regimen $(1,9,10,12)$, caution should be exercised in interpreting the results of substituting a new drug for INH in the RIF-INH-PZA regimen unless the RIF-PZA regimen is employed as a control because RIF-X-PZA may look more active than RIF-INH-PZA even if drug $\mathrm{X}$ has no activity.

Finally, this experiment again demonstrates that the twodrug combination of Pa-PZA has synergistic bactericidal activity that is as potent as RIF-INH-PZA (11). If Pa should be approved for clinical use, this combination could represent an important component of regimens to treat MDR-TB or even latent TB infection caused by MDR strains. However, because PZA cannot prevent the selection of Pa-resistant mutants, additional bactericidal agents would be required to prevent the emergence of resistance in patients with active disease.

\section{ACKNOWLEDGMENTS}

This study was supported by the Global Alliance for Tuberculosis Drug Development and the National Institutes of Health (AI 58993).

\section{REFERENCES}

1. Andries, K., P. Verhasselt, J. Guillemont, H. W. Gohlmann, J. M. Neefs, H. Winkler, J. Van Gestel, P. Timmerman, M. Zhu, E. Lee, P. Williams, D. de Chaffoy, E. Huitric, S. Hoffner, E. Cambau, C. Truffot-Pernot, N. Lounis, and V. Jarlier. 2005. A diarylquinoline drug active on the ATP synthase of Mycobacterium tuberculosis. Science 307:223-227.

2. Davies, G. R., A. S. Pym, D. A. Mitchison, E. L. Nuermberger, and J. H. Grosset. 2007. Evaluation of new antituberculosis drugs in mouse models. Antimicrob. Agents Chemother. 51:403-404.

3. Dhillon, J., J. M. Dickinson, K. Sole, and D. A. Mitchison. 1996. Preventive chemotherapy of tuberculosis in Cornell model mice with combinations of rifampin, isoniazid, and pyrazinamide. Antimicrob. Agents Chemother. 40: 552-555.

4. Dickinson, J., A. Guy, and D. A. Mitchison. 1992. Bioavailability of rifampin in experimental murine tuberculosis. Antimicrob. Agents Chemother. 36: 2066-2067.

5. Grosset, J., C. Truffot-Pernot, C. Lacroix, and B. Ji. 1992. Antagonism between isoniazid and the combination pyrazinamide-rifampin against tuberculosis infection in mice. Antimicrob. Agents Chemother. 36:548-551.

6. Lalande, V., C. Truffot-Pernot, A. Paccaly-Moulin, J. Grosset, and B. Ji. 1993. Powerful bactericidal activity of sparfloxacin (AT-4140) against Mycobacterium tuberculosis in mice. Antimicrob. Agents Chemother. 37:407-413.

7. Lecoeur, H. F., C. Truffot-Pernot, and J. H. Grosset. 1989. Experimental short-course preventive therapy of tuberculosis with rifampin and pyrazinamide. Am. Rev. Respir. Dis. 140:1189-1193.

8. Lenaerts, A. J., V. Gruppo, K. S. Marietta, C. M. Johnson, D. K. Driscoll, N. M. Tompkins, J. D. Rose, R. C. Reynolds, and I. M. Orme. 2005. Preclinical testing of the nitroimidazopyran PA-824 for activity against Mycobacterium tuberculosis in a series of in vitro and in vivo models. Antimicrob. Agents Chemother. 49:2294-2301.

9. Matsumoto, M., H. Hashizume, T. Tomishige, M. Kawasaki, H. Tsubouchi, H. Sasaki, Y. Shimokawa, and M. Komatsu. 2006. OPC-67683, a nitrodihydro-imidazooxazole derivative with promising action against tuberculosis in vitro and in mice. PLoS Med. 3:e466.

10. Nuermberger, E., I. Rosenthal, S. Tyagi, K. N. Williams, D. Almeida, C. A. Peloquin, W. R. Bishai, and J. H. Grosset. 2006. Combination chemotherapy with the nitroimidazopyran PA-824 and first-line drugs in a murine model of tuberculosis. Antimicrob. Agents Chemother. 50:2621-2625.

11. Nuermberger, E., S. Tyagi, R. Tasneen, K. N. Williams, D. Almeida, I. Rosenthal, and J. H. Grosset. 2008. Powerful bactericidal and sterilizing activity of a regimen containing PA-824, moxifloxacin, and pyrazinamide in a murine model of tuberculosis. Antimicrob. Agents Chemother. 52:15221524.

12. Nuermberger, E. L., T. Yoshimatsu, S. Tyagi, R. J. O'Brien, A. N. Vernon, R. E. Chaisson, W. R. Bishai, and J. H. Grosset. 2004. Moxifloxacin-containing regimen greatly reduces time to culture conversion in murine tuberculosis. Am. J. Respir. Crit. Care Med. 169:421-426.

13. Rosenthal, I. M., M. Zhang, K. N. Williams, C. A. Peloquin, S. Tyagi, A. A. Vernon, W. R. Bishai, R. E. Chaisson, J. H. Grosset, and E. L. Nuermberger. 2007. Daily dosing of rifapentine cures tuberculosis in three months or less in the murine model. PLoS Med. 4:e344.

14. Rosenthal, I. M., K. Williams, S. Tyagi, C. A. Peloquin, A. A. Vernon, W. R. Bishai, J. H. Grosset, and E. L. Nuermberger. 2006. Potent twice-weekly rifapentine-containing regimens in murine tuberculosis. Am. J. Respir. Crit. Care Med. 174:94-101.

15. Stover, C. K., P. Warrener, D. R. VanDevanter, D. R. Sherman, T. M. Arain, M. H. Langhorne, S. W. Anderson, J. A. Towell, Y. Yuan, D. N. McMurray, B. N. Kreiswirth, C. E. Barry, and W. R. Baker. 2000. A small-molecule nitroimidazopyran drug candidate for the treatment of tuberculosis. Nature 405:962-966.

16. Tyagi, S., E. Nuermberger, T. Yoshimatsu, K. Williams, I. Rosenthal, N. Lounis, W. Bishai, and J. Grosset. 2005. Bactericidal activity of the nitroimidazopyran PA-824 in a murine model of tuberculosis. Antimicrob. Agents Chemother. 49:2289-2293.

17. Zhang, Y., and D. Mitchison. 2003. The curious characteristics of pyrazinamide: a review. Int. J. Tuberc. Lung Dis. 7:6-21. 